\title{
Coculture of Embryonic Ventricular Myocytes and Mouse Embryonic Stem Cell Enhance Intercellular Signaling by Upregulation of Connexin43
}

\author{
Hui Li ${ }^{a}$ Ming Tang ${ }^{a}$ Huamin Liang ${ }^{a}$ Yuting Li Jian Wang ${ }^{a}$ Yuanlong Song ${ }^{a}$ \\ Yunjie Zheng $^{\mathrm{a}}$ Jiaoya Xia Jinxia Zhang ${ }^{\mathrm{a}}$ Jürgen Hescheler ${ }^{\mathrm{b}}$ Minjie Zhu ${ }^{\mathrm{a}}$ \\ aDepartment of Physiology; Chinese-German Stem Cell Center; The Key Labotory of Drug Target \\ Research and Pharmacodynamic Evaluation, Hubei Province; Tongji Medical College, Huazhong \\ University of Science and Technology, Wuhan, China; 'Institute of Neurophysiology, University of \\ Cologne, Cologne, Germany
}

\section{Key Words}

Gap junction • Connexin43 - Embryonic stem cells • Embryonic ventricular myocytes • Cardiomyocytes

\begin{abstract}
Background: Stem cell therapy has been proposed as a potential treatment strategy for ischemic cardiomyopathy in recent years. A variety of stem cells or stem cell-derived cells can potentially be used for transplantation. Despite improved cardiac function after treatment, one of the major problems is the poor integration between host and donor cells which can lead to post-transplantation arrhythmia and poor long-term outcome. Methods: In the present study, we cocultured murine embryonic stem cells (mES) with murine embryonic ventricular myocytes (mEVs) in hanging drops to assess the cellular interaction and function of mESderived cardiomyocytes under these conditions. Results: We found that when mEVs are added to a culture system of embryonic stem cells, the number of spontaneously beating areas in embryoid bodies (EBs) increases, intercellular gap junction communication is enhanced by upregulation of $\mathrm{Cx} 43$ expression at the mid-developmental stage and $\mathrm{C} \times 43$ is distributed more orderly between cardiomyocytes. Conclusions: Our findings suggest mES-derived cardiomyocytes are able to form effective signaling pathways through coculture with $\mathrm{mEVs}$ which is important for providing more functional grafts for cardiac cell therapy by improving the integration between transplanted and host cells.
\end{abstract}


Li et al.: $\mathrm{mES}$ Coculture with mEVs Promotes Cx43 Expression

\section{Introduction}

Cardiovascular disease has become the leading cause of death in both developing and developed countries [1]. Ischemic heart diseases, including myocardial infarction, are characterized by lack of blood supply and progressive loss of cardiomyocytes, finally resulting in heart failure. The heart is known as a postmitotic organ, i.e. mature cardiomyocytes have limited self-regeneration ability after damage. Cell transplantation has emerged as a potential treatment strategy for heart failure and irreparable loss of heart cells. As pluripotent embryonic stem cells (ESCs) can self-renew, proliferate and can differentiate to cell types of all three germ layers in vitro, they are an ideal source of cells for the therapy of cardiovascular diseases [2]. Though cardiac function was improved after transplantation of ES cell-derived cells, one of the major problems in the cell therapy is that the donor cells do not integrate well with the host tissue, leading to discordant functional activities between them. This may ultimately cause post-transplantation arrhythmia and poor long-term outcome [3, 4], due in part to a lack of intercellular connections.

The key for intercellular connections between cells are functional and ordered gap junctions (GJs). GJs are specialized membrane domains that mediate electrical and chemical coupling by forming cell-cell channels, thus directly connecting adjacent cells and allowing the passage of ions and small metabolites [5]. They primarily consist of proteins encoded by the connexin gene family in vertebrates. Gap junctions participate in the regulation of many physiological processes, such as embryonic development, coordinated contraction of excited cells, regulation of cell growth and differentiation, etc. [6, 7]. The connexin $\mathrm{Cx} 43$ plays a crucial role in cardiac development: mice with an inactivation of connexin 43 die shortly after birth due to an obstruction of the right ventricular outflow tract of the heart [8]. Gap junctional coupling is very important for functional integration of engrafted cells with the host myocardium $[9,10]$. General downregulation of $\mathrm{Cx} 43$ in the host myocardium was indicated to be an important factor underlying post-transplantation arrhythmia [11]. Engraftment of Cx43-expressing myocytes has the potential to reduce post-infarct arrhythmias through increasing intercellular electrical coupling between the infarcted area and the surrounding normal tissues [12]. Thus, increasing the expression of gap junction proteins might be a way to improve engraftment. Because the survival rate of adult myocardial cells is lower than that of fetal cells, it may have an adverse effect on the electrophysiological function of host muscle cells. Cx43 is the major connexin in vertebrate ventricular cardiomyocytes. In the mouse, $\mathrm{Cx} 43$ is expressed at embryonic day12.5 in the trabeculated myocardium but not in the compact tissue and is uniformly expressed across the entire ventricular myocardium by embryonic day 17.5 [13]. Cardiomyocytes derived from human ES cells display structural and functional properties of early-stage cardiomyocytes [14], are electrophysiologically immature and exhibit automaticity [15].

The microenvironment produced by direct intercellular contact, indirect cell coculture or secreted factors in conditioned medium is important in stem cell differentiation $[16,17]$. Therefore we propose to take advantage of both intercellular contact and factors released by adjacent cells to influence the co-cultured $\mathrm{mES}$ via paracrine effects and make the expression and distribution of $\mathrm{Cx} 43$ more similar to mature cardiomyocytes. Thus, we co-cultured mES cells with day $17.5 \mathrm{mEVs}$ in order to find out the effect of Cx43 expression on mES cell-derived myocardial function.

\section{Materials and Methods}

\section{Animal Care}

Adult Kunming mice were obtained from the Laboratory Animal Center, Huazhong University of Science and Technology. This study was carried out strictly according to Regulations on Laboratory Animals in Hubei Province (2005-50) and relevant guidelines, and the use of animals was approved by the China Hubei Provincial Science \& Technology Department, Permit Number: SYXK (Hubei) 2010-0057. 
Li et al.: $\mathrm{mES}$ Coculture with mEVs Promotes Cx43 Expression

Tab. 1. Sequences of primers

\begin{tabular}{|c|c|c|c|c|}
\hline Species & Gene bank & Pairs & Primer sequences (5'-3') & $\begin{array}{l}\text { Product } \\
\text { size(bp) }\end{array}$ \\
\hline$\overline{\text { GAPDH }}$ & NM_008084.2 & F & 5'-AACTTTGGCATTGTGGAAGG-3' & 132 \\
\hline cTNT & NM_001130174.2 & $\begin{array}{l}\mathrm{F} \\
\mathrm{R}\end{array}$ & $\begin{array}{l}\text { 5'-GACTTTGATGACATCCACAGGA-3' } \\
\text { 5'-ATCAGCTCCTCTTCCTCCTTCT-3' }\end{array}$ & 107 \\
\hline Connexin 43 & NM_010288.3 & $\begin{array}{l}\mathrm{F} \\
\mathrm{R}\end{array}$ & $\begin{array}{l}\text { 5'-ATCTGTCCCACCTTTGTGTCTT-3' } \\
\text { 5'-ACTTGCACACCCACACATAGAC-3' }\end{array}$ & 187 \\
\hline
\end{tabular}

Harvesting and isolation of single $m E V$ cells

Male and female mice were mated and separated in the next morning. If female mice were pregnant this was recorded as E0.5, and E17.5 was used as the late embryonic development stage [18, 19]. E17.5 pregnant female mice were sacrificed by cervical dislocation and the embryonic hearts were removed. The ventricles were separated, cut to pieces, digested into single cells using $0.1 \%$ collagenase $B[20,21]$ and resuspended in differentiation medium composed of Iscove's modified Dulbecco's medium (IMDM, Gibco, USA) supplemented with $20 \%$ fetal bovine serum (Gibco, USA), $100 \mathrm{U} / \mathrm{ml}$ penicillin, $0.1 \mathrm{mg} / \mathrm{ml}$ streptomycin, $1 \%$ nonessential amino acids, $0.1 \mathrm{mM} \beta$-mercaptoethanol (Gibco, USA)

Coculture of $m E S$ cells and $m E V s$ and differentiation

The D3 mES cell line was obtained from ATCC (CRL-1934, ATCC, USA) and cultured as described [22, 23]. In brief, the undifferentiated $\mathrm{mES}$ cells were grown on inactivated mouse embryonic fibroblasts (MEFs) with $1000 \mathrm{IU} / \mathrm{ml}$ LIF (Millipore, USA) and passaged every second day. MEFs were prepared from embryonic mice at day 14.5 and inactivated by mitomycin C (Kyowa Hakko, Japan) treatment. For differentiation, the $\mathrm{mES}$ cells were digested into a single cell suspension by $0.05 \%$ trypsin, centrifuged and resuspended in differentiation medium. For the mES-control group (ES group), mES cell differentiation was induced by embryoid body (EB) development through two days in hanging drops, five days in suspension culture and then plating stages according to the classical hanging drop culture method. For the cocultivation (CO group), the mES cells were mixed with mEVs at a ratio of 4:1 and differentiation was initiated as outlines above.

\section{Scrape Loading Dye Transfer (SLDT)}

Monolayer cells were washed with PBS for three times and covered with $0.5 \mathrm{~g} / \mathrm{L}$ Lucifer Yellow (Sigma, USA) in PBS. The monolayers were scraped with a scalpel and incubated for $5 \mathrm{~min}$, then washed with PBS and observed immediately in an inverted microscope (Nikon TE2000). The diffusion distance of Lucifer Yellow spread from the scratch on both sides was measured as an index of intercellular gap junction communication function.

\section{RT-PCR and Quantitative real-time PCR}

RNA was extracted using Trizol reagent according to the manufacturer's protocol. cDNA was synthesized by reverse transcription with oligo(dT) primers, using Superscript first strand cDNA synthesis kit (Invitrogen, USA). For PCR analysis, the expression levels of each gene were normalized to GAPDH. Data were analyzed in triplicate from at least three separate experiments. Primers were designed by Primer3 (http://frodo.wi.mit.edu/) and were synthesized by Sangon Biotech Co., Ltd. (Shanghai, China). Primer sequences are listed in Table 1.

\section{Western blot}

Total protein was prepared following the manufacturer's instructions in NP40 lysis reagent (Beyotime, China). In brief, cells were lysed in NP40 lysis buffer containing complex inhibitors and 1mM PMSF and 1mM phosphatase inhibitor. Proteins were denatured for $5 \mathrm{~min}$, resolved on a 10\% SDS-PAGE gel and transferred to nitrocellulose membranes. Membranes were blocked with 5\% non-fat milk powder in TBS containing $0.1 \%$ Tween-20 for $1 \mathrm{~h}$ at room temperature, then incubated with primary antibody against connexin 43 (CST, USA), phospho-connexin43 (CST, USA) and GAPDH (Proteintech, China) overnight at $4{ }^{\circ} \mathrm{C}$ at a dilution of 1:1000. The membranes were incubated with secondary antibody labeled with IRDye800CW (LI-COR, USA) for $1 \mathrm{~h}$ at room temperature and immunoreactive bands were detected by Odyssey infrared imaging system (LI-COR, USA). 
Fig. 1. Morphology of differentiating EBs. A-B: Forming EBs after 2 days in hanging drops ; C-D: Size of EBs increased with development and cells form compact spherical EBs; E-F: After 2 days adherent cultivation (plating on day 7), spontaneously beating areas were observed in EBs (scale bar $=200 \mu \mathrm{m}$ ).

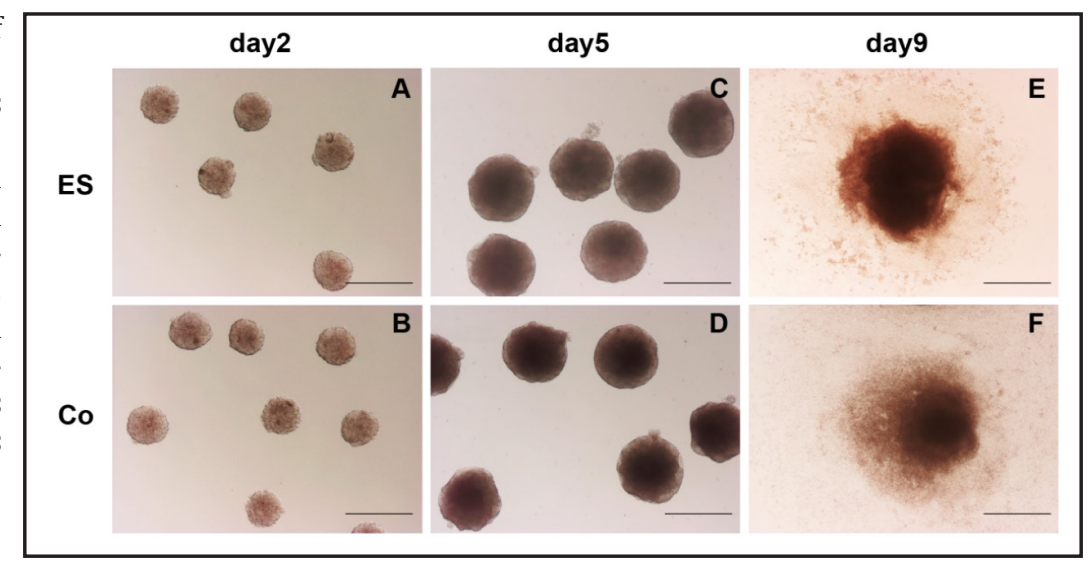

Immunofluorescence

Beating areas of EBs were dissected and digested by $0.1 \%$ Collagenase B at differentiation day 13 . The single cells were replated onto gelatin-coated glass coverslips with same cell density in two groups. After $24 \mathrm{~h}$, adherent cardiomyocytes were fixed in 4\% paraformaldehyde solution for $1 \mathrm{~h}$ at room temperature, washed with PBS, and then permeabilized with 1\% Triton-X100 for $10 \mathrm{~min}$. After blotting with 5\% BSA PBS for $1 \mathrm{~h}$, the preparations were incubated overnight at $4{ }^{\circ} \mathrm{C}$ with Connexin 43 antibody and $\alpha$-actinin antibody (Boster, China) at a dilution of 1:100. Primary antibodies were visualized by Cy3-conjugated goat anti mouse IgG $(\mathrm{H}+\mathrm{L})$ (Jackson ImmunoResearch, USA) and FITC-conjugated affinipure goat anti rabbit $\operatorname{IgG}(\mathrm{H}+\mathrm{L})$ (Proteintech, China) at a dilution of 1: 100 for $1 \mathrm{~h}$ at room temperature. The nuclei were stained with DAPI $(1 \mu \mathrm{g} / \mathrm{ml})$ for $5 \mathrm{~min}$. Images were taken by an inverted microscope (Nikon TE2000).

\section{Flow Cytometry}

In brief, EBs were dissociated into single cells at diffentiation day 13 by $0.05 \%$ trypsin, and cells were incubated with a-actinin antibody (Boster, China) at a dilution of $1: 50$ for $1 \mathrm{~h}$ at $37^{\circ} \mathrm{C}$, Cy3-conjugated goat anti mouse $\operatorname{IgG}(\mathrm{H}+\mathrm{L})$ was used as a secondary antibody. The percentage of $\alpha$-actinin positive cardiomyocytes were assessed by Flow Cytometry (BD, USA).

\section{Statistical Analysis}

All the data were collected from at least three separate experiments. All values are given as mean \pm S.E. Differences between two groups were analyzed by using Student's t-test. Results were considered statistically significant if $p<0.05$.

\section{Results}

Both ES and CO groups can differentiate into beating muscle cells

Our study used the hanging drop method to form EBs. EBs in both groups had similar morphological characteristics and they started beating on the same day of differentiation. At differentiation day 2, the mES cells aggregate into the form of spherical EBs (Fig. 1 A,B). At day 5, the sizes of EBs were similar in both groups, but in the center of the EBs, cells of the CO group were more compact than in the ES group (Fig. 1 C,D). At day 7, the EBs were transferred to a tissue culture dish for adherent culture. The cells in the EBs' center had a small volume and the cells surrounding the EBs grew extending outward, forming the growing follicle at the edge.

From day 9 spontaneously beating EBs were observed in both groups (Fig. 1 E,F), and the percentage of beating EBs was higher in the CO group than in the ES group. The difference was especially obvious from day 12 to $14(* * p<0.01$ or $* p<0.05)$. At day 13 , the rate of beating EBs in all groups reached its maximum (Fig. $2 \mathrm{~A})$ : $(88.7 \pm 4.9) \%$ of all the EBs in the CO group showed spontaneous and rhythmic contraction, yet the beating rate was $66.1 \pm$ 
Fig. 2. Percentage of beating EBs during differentiation. A. Spontaneous contraction of EBs was observed from differentiation day 9, increasing gradually up to a peak on day 13 . Results are performed as Mean \pm S.E.M. $(n=4) ; B, C$, Beating frequency of EBs. (* $p<0.05$; $\left.{ }^{* *} p<0.01\right)$.
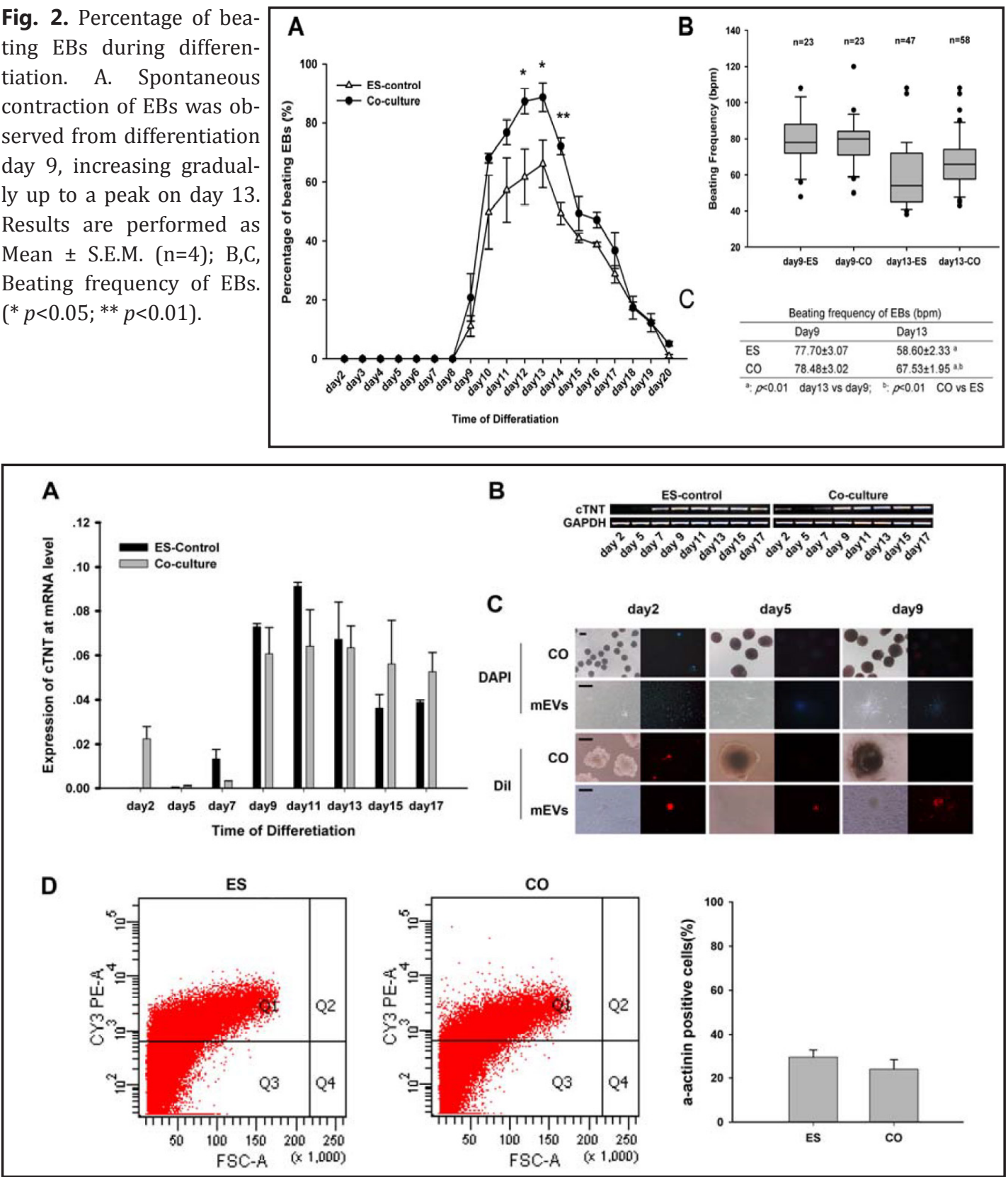

Fig. 3. Cardiac marker cTNT expressing in differentiating mES cells and labeled cell tracing. A-B: In ES group, cTNT was undetectable at first and observed from day7, from day9 it was kept at a high level. In contrast, in the CO group, cTNT was detectable at day2, almost absent at day 5 and then upregulated from day 7. No statistic difference between day 5 to day 17 was observed $(n=3)$; C: DAPI-labeled and DiI-labeled mEVs were undetectable from day 5 when cocultured with mES in suspension status, while mEVs were still detec-

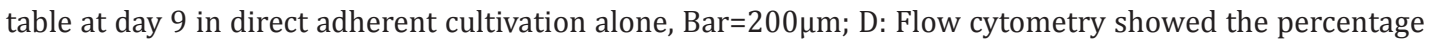
of cardiomyocytes between ES and CO groups was no differences $(29.5 \pm 3.3 \%$ vs. $24.0 \pm 4.4 \%, p>0.05, n=3)$.

7.7)\% which is lower than in the CO group $\left({ }^{*} p<0.05\right)$. It was observed that the contraction area of beating EBs was larger in the CO group compared to the ES group.

The beating frequency of EBs was also measured: at day 9 the mean beating frequency of EBs in the CO group $(n=23)$ did not differ significantly from the beating frequency of the ES group $(n=23)(77.70 \pm 3.07$ vs. $78.48 \pm 3.02 \mathrm{bpm}, p>0.05)$. Corresponding to the developmental stage, the beating frequency of EBs gradually slowed down (Fig. 2 B,C) 
Fig. 4. Gap junction communication as assessed by Scrape Loading Dye Transfer. Monolayers were prepared at day13, gap junction communication, as assessed by Scrape Loading Dye Transfer, was enhanced in the CO group (B) compared to the ES group (A). The diffusion distance of Lucifer Yellow was $45.4 \pm 0.6 \mu \mathrm{m}$ in the ES group while $85.8 \pm 1.4 \mu \mathrm{m}$ in the CO group (C) $(\mathrm{n}=8)$ $\left({ }^{* *} p<0.01\right)$. Bar $=200 \mu \mathrm{m}$.

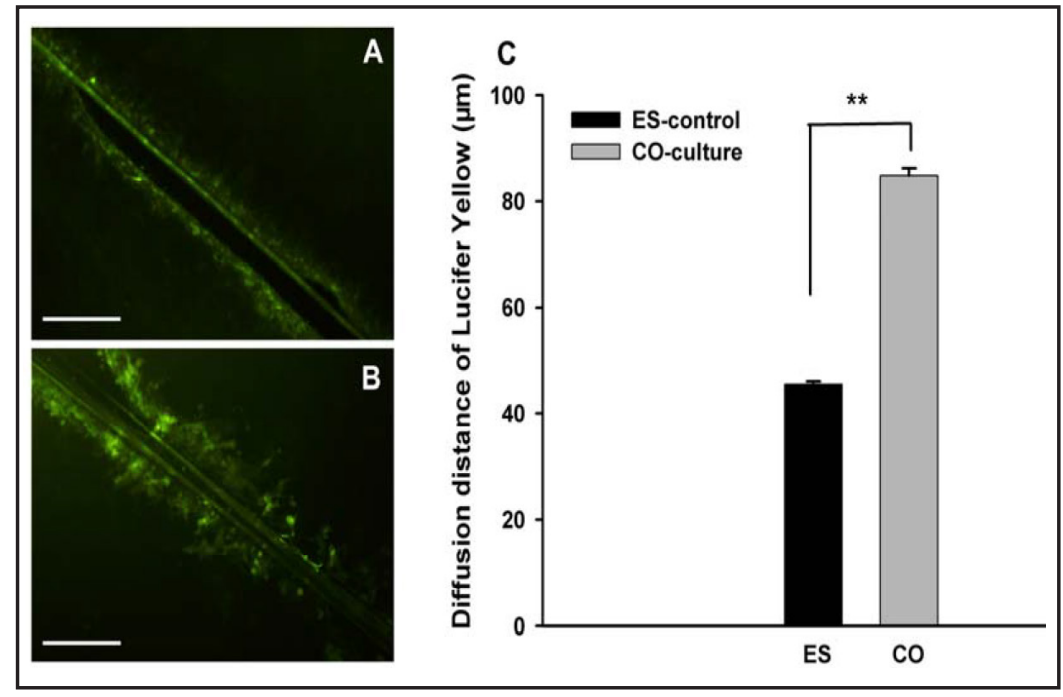

and finally stopped in both groups (Fig. 2 A). At day 13, EBs in the CO group (n=58) beat significantly faster $(67.53 \pm 1.95$ vs $58.60 \pm 2.33 \mathrm{bpm}, p<0.01)$ than the ES group $(n=47)$.

ES and CO groups show no difference in the quantity of $m E S$-derived cardiomyocytes

Expression of cardiac troponin T (cTNT), a cardiac-specific gene, was measured during differentiation. The results of RT-PCR and real-time PCR showed that cTNT mRNA levels were consistent with the cardiac differentiation: cTNT expression was undetectable at day 2-5 in the ES group, and started to be expressed at day 7. From day 9 on it was expressed at high levels. In contrast, in the $\mathrm{CO}$ group, likely due to the presence of cocultured mEV cells, cTNT was detected already at day 2 , then became almost undetectable at day 5 . With the onset of differentiation of mES cells, the resulting cardiomyocytes expressed cTNT gradually, and maintained a high expression level. There was no statistically significant difference of cTNT expression between the two groups from day 5 to 17 (Fig. 3 A,B). Similar expression patterns were observed for a-MHC (Myh6) (data not shown). We used $\alpha$-actinin as an alternative marker of cardiomyocytes, and flow cytometric results showed that there was no difference in the percentage of cardiomyocytes between ES and CO groups $(29.5 \pm 3.3 \%$ vs. $24.0 \pm 4.4 \%$, $\mathrm{p}>0.05$ ), suggesting that coculture with $\mathrm{mEVs}$ did not able to alter the cardiomyocytes differentiation rate (Fig. 3 D).

Gap junctional communication was enhanced in CO group

Our experiments showed there were more EBs with contractile areas in the CO group than in the ES group, and different beating frequencies, but no difference at the level of cardiac specific gene expression was observed. We hypothesized that the increase of beating EBs is not due to the increase of myocardial cell numbers, but due to enhanced intercellular signaling which makes more cells participate in effective contraction. Gap junction communication, as evaluated by scrape loading dye transfer, was clearly enhanced by coculture treatment $(45.4 \pm 0.6$ vs $85.8 \pm 1.4 \mu \mathrm{m})$ (Fig. 4).

\section{CX43 expression is higher in CO group than in ES group}

We therefore measured the expression of the major gap junction protein in the heart, Cx43, by PCR and Western blot at day 13. The level of Cx43 mRNA in the CO group was higher $(35 \% \pm 2 \%)$ than in the ES group at day 13 ( $p<0.01$, Fig. $5 \mathrm{~A}$ ). There was no significant difference of Cx43 mRNA expression between the two groups when measured at day 9 and day 17.

Western blotting was used to evaluate Cx43 protein expression on day 13 (Fig. 5 B) by analyzing the ratio of $\mathrm{Cx} 43$ and the housekeeping gene GAPDH. Total $\mathrm{Cx} 43$ was present in 
Fig. 5. Expression of $\mathrm{Cx} 43$ and phosphorylated $\mathrm{Cx} 43$. A: Cx43 mRNA levels were higher in the CO group at day 13. No significant difference between the two groups were observed at day 9 and day $17(\mathrm{n}=3)\left({ }^{* *} p<0.01\right) ; \mathrm{B}$ : Total Cx43 was present in four different bands, the fast non-phosphorylated form, and the slower phosphorylated Cx43; C: Total Cx43 levels were higher in the CO group than in the ES group $\left({ }^{* *} p<0.01\right) ; \mathrm{D}$ : Total $\mathrm{pCx} 43$ in the $\mathrm{CO}$ group was higher compared to the ES group $\left({ }^{* *} p<0.01\right)$, S368pCx43 levels showed no significant differences between groups $(n=4)$.

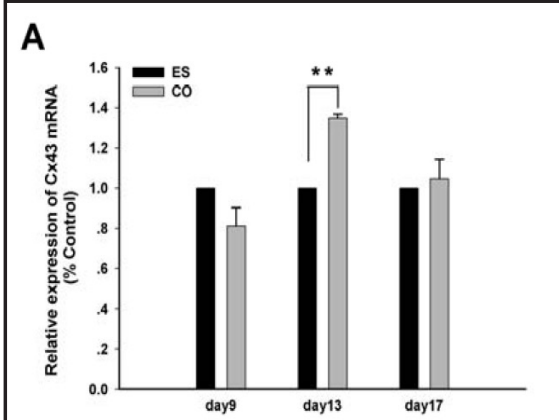

B
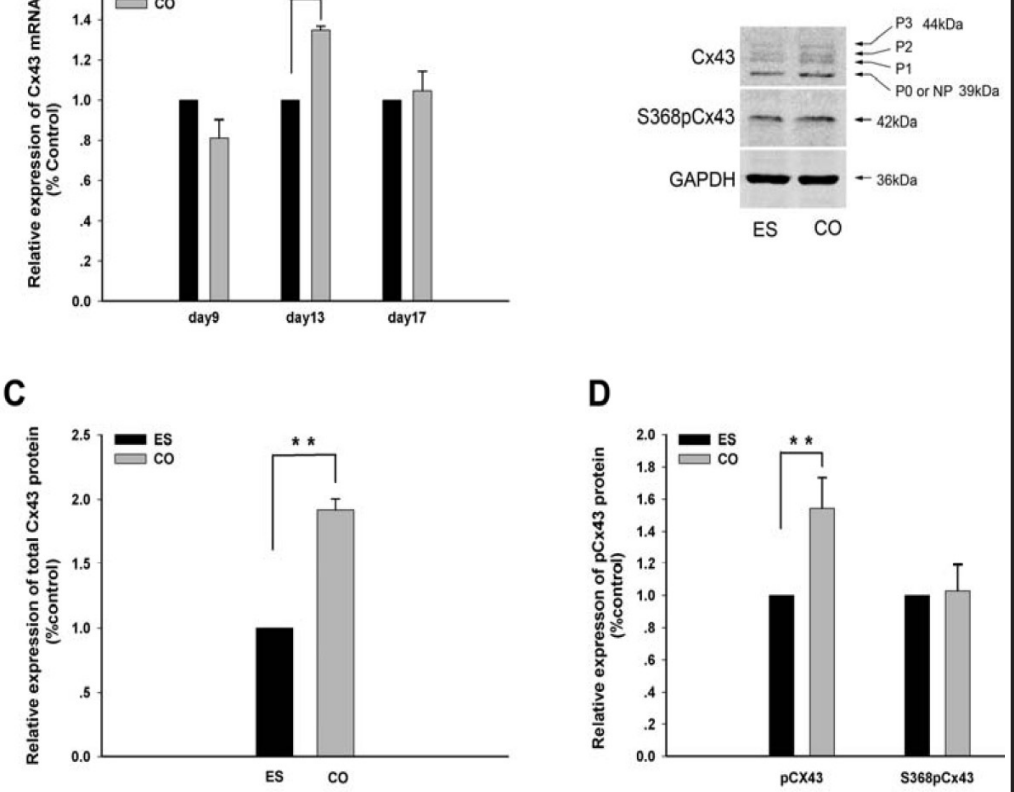

D

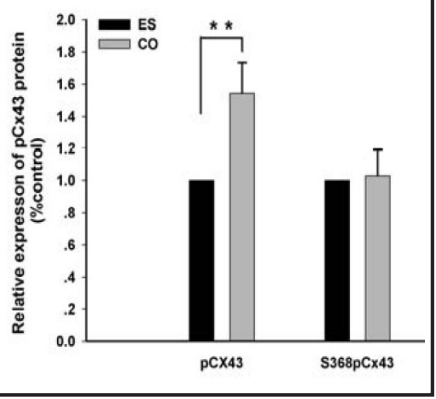

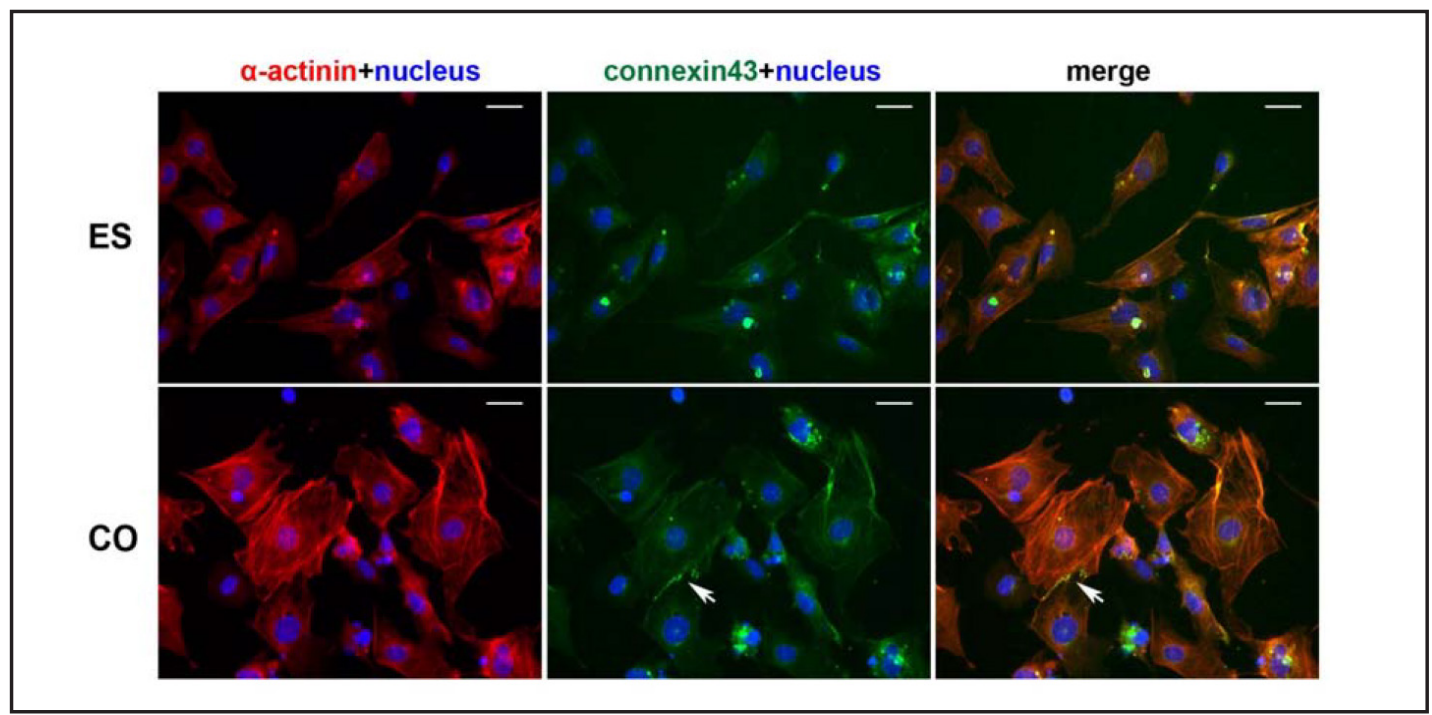

Fig. 6. Immunofluorescence staining of mES-derived cardiomyocytes. At differentiation day 13, the beating areas of EBs were dissociated into single cells, re-plated on glass coverslips and immunostained with antibody against $\alpha$-actinin and Cx43 after $24 \mathrm{~h}$ cell culture (magnification: $400 \mathrm{X}$, scale bar $=25 \mu \mathrm{m}$ ). The $\alpha$-actinin positive cells are myocardial cells. Cx43 expression were high in the CO group, and were found to be diffusely distributed in the cytoplasm and cell membrane, some $\mathrm{Cx} 43$ signals were detected in contact points of two connected cells (arrow), arranged orderly. In the ES group, Cx43 was scattered in the cytoplasm and the cell membrane.

4 different bands, the faster migrating non-phosphorylated form, and the slower migrating phosphorylated Cx43 forms P1-P3 (Fig. 5 B). Total Cx43 levels were higher in the CO group than in the ES group by $(92 \% \pm 9 \%)(p<0.01)$ at day 13 (Fig. $5 \mathrm{C})$. Phosphorylation of $\mathrm{Cx} 43$ is a dynamic process in response to activation of many different kinases, and has been 
Li et al.: $\mathrm{mES}$ Coculture with mEVs Promotes Cx43 Expression

implicated in the regulation of gap junctional communication [5]. The total phosphorylated $\mathrm{Cx} 43(\mathrm{pCx} 43)$ was calculated as $\mathrm{P} 1+\mathrm{P} 2+\mathrm{P} 3$, and total $\mathrm{pCx} 43$ was higher in the $\mathrm{CO}$ group compared to the ES group by $(54 \% \pm 19 \%)(p<0.01)$. Cx43 phosphorylation at Ser368 was measured as this phosphorylation event plays an important role in the GJ channel lifecycle, is associated with reduction in dye transfer and calcium communication and is associated with a more closed state of gap junctions [24]. However, no significant difference between the two groups was detectable (Fig. 5 D).

\section{Location of connexin 43 in both groups}

Double-label immunofluorescence was used to detect the presence and location of Cx43 in mES-derived cardiomyocytes (Fig. 6). Cx43 expression was high in the CO group; its distribution was diffuse inside the cell, and in the plasma membrane, some foci were located at regions of intercellular contacts (arrow) and were arranged in an ordered manner. In the ES group, $\mathrm{Cx} 43$ distribution was diffuse inside the cell and in the cell membrane. In the CO group, single cardiomyocytes were able to form intercellular connections rapidly.

\section{Discussion}

In this study, we demonstrated that coculture with LDS mEVs clearly increases the percentage of spontaneously contracting of EBs. We hypothesized that this increased percentage may be due to increased numbers of myocardial cells. We measured the myocardial-specific markers cTNT and Myh6. To our surprise, no difference in cTNT expression during day 5 to day 17 was observed, showing that cocultivation with immature embryonic myocardium is insufficient to induce more ES-derived cardiomyocytes. According to the RT-PCR results, no cTNT expression was initially detectable in the ES group. After 7 days, mES cell-derived myocardial cells began to express cTNT and expression reached a peak on day 13, maintaining a high level expression in the subsequent period. In contrast, because of coculture with cTNT-expressing mEVs, cTNT was detectable on day 2 in the CO group, but on day 5 cTNT was almost undetectable. To confirm the origin of cells, we labeled mEVs with DAPI or DiI, respectively. Beginning from day 5, the mEVs labeled with DAPI/Dil disappeared in CO group. Yet they still existed in mEVs control group at day 9 (Fig. 3 C). This suggested the disappearance of fluorescence was due to the lack of labeled cells, rather than due to fluorescence quenching. It might be that adherently growing mEVs lose their activity during the suspension cultivation and disappeared after day 5 , and it can also explain that from day 7 the increase of cTNT is from mES-derived cardiomyocytes rather than from the mEVs. The disappearance of labeled cells also suggested that the effect of coculture is limited to the early phase of EB formation.

Since the amount of mES-derived cardiomyocytes shows no significant changes (Fig. 3 $A, D)$, we inferred that a higher percentage of myocytes participated in contractile activities. As electrochemical signals are transferred by intercalated disc structures between mature cardiomyocytes and lead to cardiomyocyte contraction, we wondered whether the myocytes form more effective signaling pathways than in the CO group. We propose the improved beating ratio of EBs is mainly due to enhanced intercellular signaling via the gap junction intercellular communication function among the myocytes. SLDT demonstrated the rapid diffusion of signaling molecules between myocardial cells in the mid-phase of differentiation. We observed fluorescence diffusion between cells in both groups, which suggested gap junctions were formed between cardiac cells, and signals could be transferred rapidly between cardiomyocytes via gap junctions and cause more cardiac cells to get excited and contract. Fast fluorescence diffusion in the CO group suggested that more functional gap junctions were formed, leading to a increased number of beating cardiomyocytes vs. ES group.

Signal conduction and coordinated contraction are closely related to the heart gap junction protein $\mathrm{Cx} 43$. We detected a higher Cx43 mRNA expression in the CO group 
than in the ES group on day 13 when the peak number of beating EBs was observed. The migration characteristics of Cx43 in SDS-PAGE gel including both unphosphorylated (P0) and phosphorylated forms (P1, P2 and P3) were as described previously [5, 25]. Musil et al. [26] reported that the newly synthesized $\mathrm{Cx} 43$ migrates at $\mathrm{P} 0$, and is posttranslationally modified, first phosphorylated to a P1 and then to a slower migrating P2 form. We confirmed that total $\mathrm{Cx} 43$ synthesis was up-regulated in the $\mathrm{CO}$ group at the protein level. $\mathrm{Cx} 43$ is phosphorylated at multiple different serine residues during its life cycle. Phosphorylation events occur soon after $\mathrm{Cx} 43$ synthesis and change as it transfers from the endoplasmic reticulum and Golgi apparatus to the plasma membrane, ultimately forming GJ structures [27]. The phosphorylation status of $\mathrm{Cx} 43$ regulates gap junction communication. The total amount of pCx43 was increased in the CO group. Phosphorylation at different amino acid residues has different physiological effects: S368 phosphorylation by PKC is increased after ischemia [28], causing the disassembly of $\mathrm{Cx} 43$ in GJ plaques, inhibiting dye transfer and reduction of gap junctional intercellular communication $[29,30]$. Our results show that there is no difference in S368-phosphorylated Cx43 between the two groups.

Electrical excitation and ion transfer between cardiomyocytes is realized by intercalated disc structures. Intercalated discs are undulating double membranes separating myocardial cells. $\mathrm{Cx} 43$ is localized in gap junctions in intercalated discs in mature ventricular cardiomyocytes. If $\mathrm{Cx} 43$ is distributed disorderly, signal transfer between cells is impaired. Immunostaining was carried out to investigate the $\mathrm{Cx} 43$ distribution in the neighbouring cells. We demonstrated a rapid changed cardiac $\mathrm{Cx} 43$ distribution: more $\mathrm{Cx} 43$ tends to be located in the cell to cell contact points in the CO group. EBs at differentiated day 13 are equivalent to embryos at an mid-early developmental stage. Cardiomyocytes at this stage are electrophysiologically immature $[14,15]$, and $\mathrm{Cx} 43$ is distributed scattered inside the cell and in the cell membrane. Our findings suggest that the $\mathrm{Cx} 43$ distribution tends to be more mature in the $\mathrm{CO}$ group, but whether cocultivation improves the maturity of differentiated cardiomyocytes still needs to be further studied.

Cx43 protein levels were increased, the protein had a higher phosphorylation level and was distributed more orderly in the differentiated cells. We therefore concluded that mESderived cardiomyocytes express more $\mathrm{Cx} 43$ and it is located on the cell pole under coculture conditions. The phosphorylation of $\mathrm{Cx} 43$ also leads to the opening of GJ channels between adjacent cells, allowing more efficient signaling between differentiated cells in the CO group and ultimately increasing the number of beating EBs. Phosphorylation of serine/threonine residues is closely related to GJ opening and function. Phosphorylation of some residues, for example Ser364, S365, S369, which is mediated by PKA, increasing synthesis of Cx43, promoting the move of $\mathrm{Cx} 43$ to the plasma membrane, strengthening GJ assembly, enhancing GJ function [7, 31-33], may be involved in those phosphorylation events.

\section{Conclusion}

Since the mid-phase of differentiation, the percentage of beating EBs increased obviously in the $\mathrm{CO}$ vs. the ES group. The molecular diffusion rate increased between beating cardiomyocytes and the ability of gap junction assembly improved significantly in the CO group by upregulation of $\mathrm{Cx} 43$ both at the mRNA and protein levels and $\mathrm{Cx} 43$ was located regularly between cardiomyocytes. Increase of $\mathrm{Cx} 43$ expression may be relevant to its increased phosphorylation, perhaps signaling molecules released from LDS EVMs regulated the phosphorylation of $\mathrm{Cx} 43$, thereby promoting $\mathrm{Cx} 43$ expression and functional maturity. Our study showed that utilization of the micro-environment provided by LDS EVMs to differentiate ESCs can effectively promote formation and docking of intercellular gap junctions after the mid-development phase of ESC, so as to promote signaling transmission between myocardial cells. We can take advantage of it to provide mature grafts for cardiac cell therapy, promote functional integration between transplanted cells and host cells, so as to improve cardiac function. 
Li et al.: mES Coculture with mEVs Promotes Cx43 Expression

\section{Conflict of Interest}

There is no conflict of interest.

\section{Acknowledgements}

This work was co-financed by "the Fundamental Research Funds for the Central Universities", HUST (No.2011QN230) for Minjie Zhu and HUST (No. 2172012ZHYX019) for Ming Tang; Science Foundation of Huazhong University of Science and Technology (No.0109510855) for Hui Li; and by Specialized Research Fund for the Doctoral Program of Higher Education (No.20070487012) for Ming Tang.

\section{References}

1 Lopez AD, Mathers CD, Ezzati M, Jamison DT, Murray CJ: Global and regional burden of disease and risk factors, 2001: systematic analysis of population health data. Lancet 2006;367:1747-1757.

2 Choi SH, Jung SY, Kwon SM, Baek SH: Perspectives on stem cell therapy for cardiac regeneration. Circ J 2012;76:1307-1312.

- 3 Liao SY, Liu Y, Siu CW, Zhang Y, Lai WH, Au KW, Lee YK, Chan YC, Yip PM, Wu EX, Wu Y, Lau CP, Li RA, Tse HF: Proarrhythmic risk of embryonic stem cell-derived cardiomyocyte transplantation in infarcted myocardium. Heart Rhythm 2010;7:1852-1859.

-4 Liu Y, Tse HF: The proarrhythmic risk of cell therapy for cardiovascular diseases. Expert Rev Cardiovasc Ther 2011;9:1593-1601.

-5 Solan JL, Lampe PD: Connexin43 phosphorylation: structural changes and biological effects. Biochem J 2009;419:261-272.

6 Laird DW: Life cycle of connexins in health and disease. Biochem J 2006;394:527-543.

7 Söhl G, Willecke K: Gap junctions and the connexin protein family. Cardiovasc Res 2004;62:228-232.

-8 Eckardt D, Kirchhoff S, Kim JS, Degen J, Theis M, Ott T, Wiesmann F, Doevendans PA, Lamers WH, de Bakker JM, van Rijen HV, Schneider MD, Willecke K: Cardiomyocyte-restricted deletion of connexin43 during mouse development. J Mol Cell Cardiol 2006;41:963-971.

-9 Ramkisoensing AA, Pijnappels DA, Swildens J, Goumans MJ, Fibbe WE, Schalij MJ, de Vries AA, Atsma DE: Gap junctional coupling with cardiomyocytes is necessary but not sufficient for cardiomyogenic differentiation of cocultured human mesenchymal stem cells. Stem Cells 2012;30:1236-1245.

10 Thompson SA, Burridge PW, Lipke EA, Shamblott M, Zambidis ET, Tung L: Engraftment of human embryonic stem cell derived cardiomyocytes improves conduction in an arrhythmogenic in vitro model. J Mol Cell Cardiol 2012;53:15-23.

11 Coppen SR, Fukushima S, Shintani Y, Takahashi K, Varela-Carver A, Salem H, Yashiro K, Yacoub MH, Suzuki K: A factor underlying late-phase arrhythmogenicity after cell therapy to the heart: global downregulation of connexin43 in the host myocardium after skeletal myoblast transplantation. Circulation 2008;118:S138-S144.

$\checkmark 12$ Roell W, Lewalter T, Sasse P, Tallini YN, Choi BR, Breitbach M, Doran R, Becher UM, Hwang SM, Bostani T, von Maltzahn J, Hofmann A, Reining S, Eiberger B, Gabris B, Pfeifer A, Welz A, Willecke K, Salama G, Schrickel JW, Kotlikoff MI, Fleischmann BK: Engraftment of connexin 43-expressing cells prevents postinfarct arrhythmia. Nature 2007;450:819-824.

13 Coppen SR, Kaba RA, Halliday D, Dupont E, Skepper JN, Elneil S, Severs NJ: Comparison of connexin expression patterns in the developing mouse heart and human foetal heart. Mol Cell Biochem 2003;242:121-127.

14 Kehat I, Kenyagin-Karsenti D, Snir M, Segev H, Amit M, Gepstein A, Livne E, Binah O, Itskovitz-Eldor J, Gepstein L: Human embryonic stem cells can differentiate into myocytes with structural and functional properties of cardiomyocytes. J Clin Invest 2001;108:407-414. 
Li et al.: mES Coculture with mEVs Promotes Cx43 Expression

15 Kim C, Majdi M, Xia P, Wei KA, Talantova M, Spiering S, Nelson B, Mercola M, Chen HS: Non-cardiomyocytes influence the electrophysiological maturation of human embryonic stem cell-derived cardiomyocytes during differentiation. Stem Cells Dev 2010;19:783-795.

16 Ou DB, He Y, Chen R, Teng JW, Wang HT, Zeng D, Liu XT, Ding L, Huang JY, Zheng QS: Three-dimensional coculture facilitates the differentiation of embryonic stem cells into mature cardiomyocytes. J Cell Biochem 2011;112:3555-3562.

17 Uosaki H, Andersen P, Shenje LT, Fernandez L, Christiansen SL, Kwon C: Direct contact with endodermlike cells efficiently induces cardiac progenitors from mouse and human pluripotent stem cells. PLoS One 2012;7:e46413.

18 Liang HM, Tang M, Liu CJ, Luo HY, Song YL, Hu XW, Xi JY, Gao LL, Nie B, Li SY, Lai LL, Hescheler J: Muscarinic cholinergic regulation of l-type calcium channel in heart of embryonic mice at different developmental stages. Acta Pharmacol Sin 2004;25:1450-1457.

-19 Song GL, Tang M, Liu CJ, Luo HY, Liang HM, Hu XW, Xi JY, Gao LL, Fleischmann B, Hescheler J: Developmental changes in functional expression and beta-adrenergic regulation of $\mathrm{i}(\mathrm{f})$ in the heart of mouse embryo. Cell Res 2002;12:385-394.

20 Liu A, Tang M, Xi J, Gao L, Zheng Y, Luo H, Hu X, Zhao F, Reppel M, Hescheler J, Liang H: Functional characterization of inward rectifier potassium ion channel in murine fetal ventricular cardiomyocytes. Cell Physiol Biochem 2010;26:413-420.

-21 Nie L, Tang M, Zeng Y, Jiang H, Shi H, Luo H, Hu X, Gao L, Xi J, Liu A, Reppel M, Hescheler J, Liang H: Properties and functions of katp during mouse perinatal development. Biochem Biophys Res Commun 2012;418:74-80.

22 Sachinidis A, Fleischmann BK, Kolossov E, Wartenberg M, Sauer H, Hescheler J: Cardiac specific differentiation of mouse embryonic stem cells. Cardiovasc Res 2003;58:278-291.

23 Hescheler J, Fleischmann BK, Lentini S, Maltsev VA, Rohwedel J, Wobus AM, Addicks K: Embryonic stem cells: a model to study structural and functional properties in cardiomyogenesis. Cardiovasc Res 1997;36:149-162.

24 Straub AC, Johnstone SR, Heberlein KR, Rizzo MJ, Best AK, Boitano S, Isakson BE: Site-specific connexin phosphorylation is associated with reduced heterocellular communication between smooth muscle and endothelium. J Vasc Res 2010;47:277-286.

25 Lampe PD, Kurata WE, Warn-Cramer BJ, Lau AF: Formation of a distinct connexin43 phosphoisoform in mitotic cells is dependent upon p34cdc2 kinase. J Cell Sci 1998;111:833-841.

-26 Musil LS, Cunningham BA, Edelman GM, Goodenough DA: Differential phosphorylation of the gap junction protein connexin43 in junctional communication-competent and -deficient cell lines. J Cell Biol 1990;111:2077-2088.

27 Solan JL, Lampe PD: Key connexin 43 phosphorylation events regulate the gap junction life cycle. J Membr Biol 2007;217:35-41.

28 Ek-Vitorin JF, King TJ, Heyman NS, Lampe PD, Burt JM: Selectivity of connexin 43 channels is regulated through protein kinase c-dependent phosphorylation. Circ Res 2006;98:1498-1505.

29 Marquez-Rosado L, Solan JL, Dunn CA, Norris RP, Lampe PD: Connexin43 phosphorylation in brain, cardiac, endothelial and epithelial tissues. Biochim Biophys Acta 2012;1818:1985-1992.

-30 Bao X, Reuss L, Altenberg GA: Regulation of purified and reconstituted connexin 43 hemichannels by protein kinase c-mediated phosphorylation of serine 368. J Biol Chem 2004;279:20058-20066.

-31 Yogo K, Ogawa T, Akiyama M, Ishida-Kitagawa N, Sasada H, Sato E, Takeya T: Pka implicated in the phosphorylation of cx43 induced by stimulation with fsh in rat granulosa cells. J Reprod Dev 2006;52:321328.

-32 Solan JL, Lampe PD: Connexin phosphorylation as a regulatory event linked to gap junction channel assembly. Biochim Biophys Acta 2005;1711:154-163.

-33 TenBroek EM, Lampe PD, Solan JL, Reynhout JK, Johnson RG: Ser364 of connexin43 and the upregulation of gap junction assembly by camp. J Cell Biol 2001;155:1307-1318. 